\title{
Ureter Urothelial Carcinoma
}

National Cancer Institute

\section{Source}

National Cancer Institute. Ureter Urothelial Carcinoma. NCI Thesaurus. Code C4830.

A carcinoma that arises from the transitional epithelium of the ureter. It is associated with tobacco use and usually presents with gross or microscopic hematuria. 